\title{
O SER EM HEGEL E OS JULGAMENTOS VIRTUAIS
}

\section{Thiago Aércio de Queiroz ${ }^{140}$}

Recebido em: 21/10/2019

Aprovado em: 06/02/2020

\section{RESUMO}

A marca da modernidade líquida tem sido o imediatismo da satisfação. Busca-se a todo custo alcançar a satisfação do objeto almejado em menor tempo possível, atribuindo-se a isto a denominada efetividade. A celeridade proporcionada pela virtualização afetou as relações humanas em diversas ordens, sobretudo a ordem jurisdicional, o que acabou por atingir as bases afetivas em nome do apregoado progresso. A implementação de um sistema que minimiza e por vezes substitui a análise cognitiva humana invadiu o espaço do ser que julga e do que é julgado, olvidando da racionalidade intrínseca na relação social jurídica enquanto ciências humanas, proporcionando assim uma robotização de decisões que afetam diretamente toda uma sociedade, Portanto neste trabalho será utilizado como técnica metodológica a pesquisa teórica e análise conceitual voltado para o "ser" na dialética Hegeliana.

Palavras-chave: Ser. Julgamento virtual. Ciências sociais aplicadas. Filosofia.

\section{INTRODUÇÃO}

A sociedade, segundo BAUMAN $(2009$, p.07) “em que as condições sob as quais agem os membros mudam num tempo mais curto do que aquele necessário para a consolidação, em hábitos e rotinas, da forma de agir, marcam o período vigente, denominado de modernidade líquida". A "vida líquida"é a forma de se viver para atender a modernidade líquido-moderna .

A "vida líquida" e "modernidade - líquida" são um círculo vicioso. Procura-se produzir mais em menos tempo como eficiência para o consumo imediato. Consumir é prazeroso, o que provoca alcançá-lo em imediato e possibilidade da sensação de mais prazeres num período menor

${ }^{140}$ Doutorando em Teoria do Direito pela Pontifícia Universidade Católica de Minas Gerais (PUC Minas).. 
de tempo que, para ser fomentado demanda maior celeridade na produção, também maior velocidade no descarte das coisas, incluindo nisso o ser humano. Logo, as relações se fazem cada vez mais frias, rápidas, efêmeras, em nome da suposta eficiência.

\begin{abstract}
Numa sociedade líquido-moderna, a indústria de remoção do lixo assume posições de destaque na economia da vida líquida. A sobrevivência dessa sociedade e o bem-estar de seus membros dependem da rapidez com que os produtos são enviados aos depósitos de lixo e da velocidade e eficiência da remoção dos detritos. Nessa sociedade, nada pode ter permissão de se tornar indesejável. A constância, a aderência e a viscosidade das coisas, tanto animadas quanto inanimadas, são os perigos mais sinistros e terminais, as fontes dos temores mais assustadores e os alvos de ataques mais violentos” (BAUMAN, 2009, p. 08)
\end{abstract}

No mês de novembro de 2017 o Tribunal de Justiça de Minas Gerais julgou inédita e virtualmente 280 processos em um instante. Isto é a sequência do enredo pós-moderno que em nome do progresso utiliza a máquina virtual em substituição ao humano.

Diante do alto e crescente número de demandas dos processos judiciais, parece à primeira vista, que o referido procedimento é eficiente e eficaz. No entanto, omite-se da central questão enquanto ciências humanas que é o "ser" e o necessário discurso racional, pois o programa virtual se baseia na lógica efetuada por logaritmos matemáticos. Eis o nome de sua inteligência: artificial.

Assim, enquanto o direito se tratar de ciências sociais aplicadas, o requisito é a racionalidade humana, ou seja, que o "Ser" é a essência. Vale nisso a lição de Hegel ao elucidar que "a substância viva é o ser, que na verdade é sujeito, ou - o que significa mesmo - que é na verdade efetivo, mas só na medida em que é o movimento de pôr-se a si mesmo, ou a mediação consigo mesmo do tornar-se outro" (HEGEL, 2017, p. 32).

O "ser” é a relação do sujeito com o objeto, essa operação há de existir em singular tempo e espaço, mudando a cada instante e lugar, não se repete como tenta simular a inteligência artificial. Portanto, a programação de repetição deste tipo de inteligência não permitirá o “ser”, logo, não há ciências humanas ou sociais aplicadas.

Sobre os julgamentos virtuais pelo Tribunal de Justiça de Minas Gerais:

O desembargador (...) explicou que, depois que a ferramenta separa os recursos, é montado um padrão de voto que contempla matéria já decidida pelos Tribunais Superiores, ou pelo Incidente de Resolução de Demandas Repetitivas (IRDR), processo que trata de um assunto abordado em inúmeros outros processos. Assim, depois que o incidente é julgado, a mesma decisão deve ser aplicada a todas as outras ações judiciais do mesmo teor (TJMG. 2018. p. 1) 
A tentativa de aplicar decisões de um mesmo teor á casos distintos é falha, uma vez que tratará situações diversas de igual modo, no entanto diz respeito a algo novo, como assevera Heráclito de Éfeso: "ninguém pode se banhar duas vezes no mesmo rio, pois nem ele e o rio são os mesmos"(BITTAR; ALMEIDA apud HERÁCLITO 2015, p. 89).

A inteligência artificial atua aplicando decisões proferidas por Tribunais Superiores em julgados anteriores a novos casos, na medida em que possuem conteúdos relacionados. Quando os demais Tribunais admitirem a inteligência artificial, faltariam, então, as decisões de inteligência humana para fomentar o paradigma ao programa de computador, uma vez que o artificial busca ser espectro dos decididos por deliberações entre julgadores humanos.

Buscará demonstrar neste estudo que o "ser” não poderá ausentar-se das decisões humanas, sobretudo aos discursos jurídicos, já que nestes há requisitos para sua validade, conforme no magistério de Alexy:

As regras do discurso racional se referem não só, como regras da lógica, a enunciados, mas também, além disso, ao comportamento do falante, constituindo uma tarefa de uma teoria do discurso prático racional estabelecer um tal sistema de regras e formas, fundamentá-lo e verificar sua consistência e eficiência. (ALEXY, 2014. p. 40.)

As decisões por inteligência artificial alastram outro defeito: são ausentes de deliberação argumentativa antes da própria relação do "ser" para com o objeto. No desenvolvimento deste artigo, buscar-se-á demonstrar o caminho tendencioso da anulação do "ser", as regras do discurso jurídico com suas distinções das ciências exatas e as consequências da robotização do homem, que o distancia ainda mais da justiça, segundo a pesquisa teórica na sociologia de Bauman e da dialética de Hegel discorrida na obra "Fenomenologia do Espírito"

\section{O PROCESSO PENAL NA PÓS-MODERNIDADE}

Segundo Bauman, a relação entre as pessoas já foi mais segura, isto quando dependia de investimento de tempo e esforços, mas que tem sido sacrificada em nome de interesses individuais imediatos. Tal fato é o motivo pelo qual, sente-se o enfraquecimento das relações sociais, não mais atendida por sistema estrutural, mas de "rede" cuja dinâmica é por conexões e desconexões 
aleatórias de diversas permutas, atendendo ao imediatismo, dando vasão a premissa de que o egoísmo tem sido mais eficiente. (BAUMAN, 2007)

Nesses termos, o sistema virtual ocupa cada dia mais o espaço que antes eram exercidos por humanos. Não é diferente na operação do Direito, o qual até então utilizava da máquina virtual para eficiência de seus procedimentos, resguardando a inteligência humana para a racionalidade nos julgamentos, até que no dia 7 de novembro de 2018, quando o Tribunal de Justiça de Minas Gerais inaugurou os julgamentos por meio virtual, o que pode ir contra a distribuição da justiça.

Para se chegar até a problemática da hipótese, partindo-se do período moderno marcado pela Revolução Francesa, perpassando o contrato social, até enfim a instituição de democracia por República Federativa, o objetivo teórico é de igualdade.

A igualdade é o fundamento político social que rege os princípios do Direito nas ciências criminais, construindo o famigerado "devido processo penal”, a custos altos, é uma conquista pesada em prol da isonomia, cuja fundamentação é a importância da igualdade, - humanos são iguais-. Portanto, assegurando-se a dignidade enquanto ser humano. O filósofo Kant, sobre a moralidade explica:

No reino dos fins tudo tem ou um preço ou uma dignidade. Quando uma coisa tem um preço, pode-se pôr em vez dela qualquer outra como equivalente; mas quando uma coisa está acima de todo o preço, e portanto não permite equivalente, então tem ela dignidade. (KANT. 1786. p.96)

A profundidade do significado em "ser humano" faz erigir o sentido axiológico do próprio “ser”. Alguém “é” dever ser, permitindo a liberdade intrínseca neste próprio sentido. Em “Carta sobre o humanismo", Martin Heidegger (2005) bem esclarece:

\footnotetext{
A existência somente se pode dizer da essência do homem, isto é, somente a partir do modo humano de "ser;". pois, apenas o homem, ao menos tanto quanto sabemos, nos limites da nossa experiência, está iniciado no destino da existência. É por isso que a existência nunca poderá ser pensada como uma maneira específica de ser entre outras espécies de seres vivos; isto naturalmente supondo que o homem foi assim disposto, o que deve pensar a essência do seu ser e não apenas elaborar relatórios sobre a natureza e a história da sua constituição e das suas atividades. (HEIDEGGER. 2005. p.24)
}

Eis a razão de ser dos princípios constitucionais fundamentais que na vertente do direito processual penal dá forma ao devido processo legal, assegurando a igualdade das partes, presunção de inocência, direito de defenderem-se pelo contraditório que, para este último, é imprescindível 
as fundamentações de todas as decisões judiciais, justamente para manter possível a dialética do discurso jurídico racional como ciências humanas aplicadas.

Na modernidade-líquida o direito de defesa tolhido em nome da equivocada eficiência. As raízes filosóficas que floresceram o tema humanístico vêm desvanecendo progressivamente. O penalismo de nível médio foi abandonando sua velha pretensão de coerência filosófica e empobrecendo seu discurso até tornar comum a mistura arbitrária de elementos de ideologias incompatíveis (ZAFFARONI, 2001).

A sociedade é acometida da maximização da quantidade e qualidade de crimes conforme propagado pela imprensa que é exaustiva e provoca a opinião pública a reclamar uma postura imediata do Estado frente ao problema. É uma característica da modernidade como um todo, que neste caso Bechara denomina "sociedade de risco", ao estudar a teoria do sociólogo Ulrich Beck. (BECHARA, 2008)

Nesta sistemática da grande vulnerabilidade, consequentemente tende elevar a sensibilidade ao risco, ou seja, o temor se mostra maior que de fato é, levando ao sofrimento de insegurança, efeito proporcionado pela celeridade de informações midiáticas, culminando na pretensão social de que ao Estado cabe, através do "soldado de reserva", ora Direito Penal, fornecer resposta de emergência e impactante. (BECHARA, 2008)

A deslegitimação dos sistemas penais e o desprestígio dos discursos jurídicos-penais não se produziram abruptamente no marco teórico os países centrais, mas resultaram de um longo processo de revelação de dados reais, acompanhado de um paralelo empobrecimento filosófico do discurso jurídico - penal, que permitiu a sobrevivênciaquase intactas neste discurso - de concepções do homem ou de antropologias filosóficas há muitas décadas desaparecidas das correntes gerais do pensamento. (BECHARA, 2008, p.413)

Esquece-se do "ser" enquanto humano igual, portanto, digno de individualidade, de maneira a exceder as árduas conquistas filosóficas do humanismo. Os seres são divididos em grupos como se iguais fossem, punindo o que supõe ser e não propriamente o fato, assim neste trajeto que toma maior velocidade, foi reduzido o tempo para sustentação oral da defesa no Tribunal de Segunda Instância e debates no procedimento do Tribunal do Júri, a criação de múltiplos tipos penais, a regra geral para o cumprimento da pena provisória a partir das decisões em Segunda Instância, e em caso de decisões pelo plenário do Júri é a partir de Primeira Instância. A questão que se apresenta é acerca do julgamento em Segunda Instância por inteligência artificial, da qual decide virtualmente centenas de casos ao mesmo instante, reconhecendo o tipo de ação processual e 
resposta ao suposto tipo penal pelas decisões de semelhantes casos julgados em outros Tribunais, não de acordo com o "ser".

Como leciona Brandão (2010, p.18), “os mais perigosos são os donos da verdade, os que não têm dúvidas e não se comprometem com seu próprio pensar e com seu desejo, agem burocraticamente renunciando à subjetividade" (BRANDÃO, 2010, p. 18). Porém, não há deliberação, inexistindo a conexão do homem que julga com o outro julgador, que formaria o colégio, muito menos deste para com o homem julgado.

O aborto do sujeito parte do processo é abandonado em nome da eficiência. A história de um homem representa em si o que ele é, não sendo composta apenas pelo seu passado, mas também pelo seu futuro. O homem não é apenas o que um dia foi, ele também é o que poderá ser. Isto é tão verdade, assevera Carnelutti (2012), que o próprio Código Penal determina na sentença considera dar a conduta do réu em vários momentos, antes, durante e após o delito, como na execução da pena.

Cada julgamento, para ser justo, deveria ser feito tendo-se em consideração a história toda do acusado, mas um julgamento assim só seria possível depois da morte. É como dizem os homens do negócio: não se podem apurar as contas de um balanço, senão depois de findo o exercício. Essa é a razão de a Igreja nunca realizar o processo de beatificação de pessoas vivas, só de mortas. Enquanto se respira, nunca se sabe, sempre existe a possibilidade de um canalha se converter em um homem de bem, e um homem de bem, em um canalha. Vale lembrar a experiência do ladrão da cruz. (CARNELUTTI, 2012, p. 80)

O exemplo de caso prático citado pelo autor demonstra uma parcela da omissão da história do ser, o qual é fruto do que foi, do que é e poderá vir a ser. O abandono da filosofia e o aumento do egoísmo, por mais que prometa trazer a ordem, é do contrário, um retrocesso caminho à irracionalidade e ao caos. Certamente em menos de um segundo não seriam observados a história de cada um dos 280 seres processados na Sessão inédita da $8^{\text {a }}$ Câmara Cível do Tribunal de Justiça de Minas Gerais, julgados por um click. (TJMG, 2009, p.8)

Esta é a marca da sociedade líquida, no entanto, Bauman (2009adverte que prever tendências futuras a partir de eventos passados torna-se cada dia mais arriscado e, frequentemente enganoso. É cada vez mais difícil calcular com exatidão para prognósticos seguros que são inimagináveis. 


\section{O SER (VERDADE) E SUA ESSÊNCIA}

"O verdadeiro é o todo, mas somente a essência que se implementa através de seu desenvolvimento" (HEGEL, 2017, p. 33). Entretanto, é necessário desvendar o como se dá o genuíno "ser".

Hegel (2017) inicia sua obra criticando o prefaciar, já que em filosofia não haveria possibilidade de esboçar relação da verdade filosófica, pois esta acontece no devir, é um singular fenômeno, residindo à filosofia no elemento da universalidade, incluindo a essência na sua particularidade.

Cita-se como exemplo o procedimento da anatomia, partindo do consenso de que ainda não está na posse da coisa específica, mas considera o geral num conglomerado de conhecimentos do mesmo modo histórico, como órgão, músculos e outros, que leva o nome de ciência, embora não merecesse. Isso, pois, filosoficamente é inadequado denominar ciência o citado modo, já que esta se declara incapaz de apreender o verdadeiro.

Muitas das vezes a rigidez de opinião comum se reduz apenas em mera oposição entre verdadeiro e falso, não observando a universalidade que coexiste, falha em aceitar como esclarecimento como este ou aquele, apenas. A verdade é desenvolvida progressiva e filosoficamente, não limitada em rasa contradição, conforme a dialética hegeliana.

A título de exemplo, o botão e a flor, esta última refuta o primeiro, tal qual o fruto permite ver a flor como um "ser" falso, mas estas meras distinções não demonstram a infinitude e fluidez da vida, o que é a verdade. Portanto, botão e flor não se contradizem, mas se compreendem num mesmo processo. Ou seja, a "coisa" não se esgota em seu fim, e sim na atualização do contrário, a verdade antiga seria a mesma da atualidade, caso não considere a fluidez contínua e inexistência de padronização metodológica para evidenciar o sentido do que "é". Ainda que delongas explicações deem aparência de atender a essencialidade, não atende, ante a continuidade eterna do "ser".

Assim Hegel (2017) ratifica que a "coisa" não se esgota em seu fim, mas em atualização e que seu resultado não é o todo efetivo. Ainda de acordo com o autor: "como a tendência é o mero impulso ainda carente de sua efetividade; o resultado nu é o cadáver que deixou atrás de si a tendência. Igualmente, a diversidade é, antes, o limite da Coisa: está alo onde a coisa deixa de ser; ou é o que a mesma não é” (HEGEL, 2017, p. 24) 
Destarte, o verdadeiro é o "vir-a-ser" de si mesmo, o círculo que pressupõe seu fim como sua meta, não o resultado por análise premeditada e metódica, ora exteriorizada à consciência e inteligibilidade. A natureza do verdadeiro consiste em ser algo efetivo, em ser sujeito ou vir a ser de si mesmo. (HEGEL, 2017)

A compreensão, lamentavelmente, tem se resumido em apenas se ocupar com o fim ou resultados, pois é assim mais fácil do que se ater com a própria “coisa”, no entanto, passar ignorar tal observância é mais simples do que analisar seu conteúdo devido. Conforme afirma o autor: "Nada mais fácil do que julgar o que tem conteúdo e solidez; apreendê-lo é mais difícil; e o que há de mais difícil é produzir sua exposição, que unifica ambos” (HEGEL, 2017, p. 25).

Hegel (2017) prossegue seu magistério elucidando que a cultura se esforça continuamente visando adquirir conhecimentos e princípios de pontos de vistas universais, para concluir o que se pensa da coisa em geral após análise completa de defesa e refutação, a fim de emitir juízo a seu respeito, até que firmado o seu conceito ao que merece corresponde-la. Ou seja, a verdade existe a partir de sistema científico.

Muito embora a filosofia pretenda se aproximar do referido método científico, distingue o seu significado de "amor ao saber" para com "o saber efetivo":

Reside na natureza do saber a necessidade interior de que seja ciência, e somente a exposição da própria filosofia será uma explicação satisfatória a respeito. Porém, a necessidade exterior é idêntica á necessidade interior - desde que concebida de modo universal e prescindindo da contingência da pessoa e das motivações individuais - e consiste na figura sob a qual uma época representa o ser-aí de seu momento. (HEGEL, 2017, p. 25)

Nesses termos o autor entende que a razão singular destas tentativas a visarem este fim é tentar dizer que a filosofia foi elevada ao nível de ciência, pois, ao demonstrar a sua necessidade, está, ao mesmo tempo, atingindo a sua meta.

Ainda segundo Hegel (2017), dizer que tratar a verdade com fundamento científico, que é o mesmo de poder afirmar o que é verdade, pode estar em contradição com algo filosófico, pois doutro modo o verdadeiro existe pela intuição, ou seja, o imediato do absoluto, como a religião, em exemplo. Portanto, o absoluto não é conceito, mas sentido e intuído, eis que se trata de um sentimento expressado.

Então na evolução da exigência, o sentido de verdade foi além do nível que presentemente se encontra o espírito consciente de si. Além disso, antes levava-se por elemento de fé, para outra 
reflexão, ora científica, sendo esta o suprimento da carência de si sobre si. Mais que isso, agora a filosofia exige nem tanto o saber "do que é”, mas regata a densidade e substância do "ser".

Pretende-se então misturar as distinções do pensamento, reprimir o conceito que diferencia, restaurando o "sentimento da essência". "O "belo", o sagrado, a religião, o amor são a isca requerida para despertar o prazer do mordiscar" (HEGEL, 2017, p. 27).

Ressalta-se que não se finda o conceito, mas o êxtase. Assim não é a fria e inerte necessidade metódica da Coisa, como mero padrão procedimental científico que consiste a substância, mas, sim o entusiasmo abrasador, sendo este o fenômeno singular. (HEGEL, 2017).

Exemplificar que o homem não se contentava com o sensível, vulgar, como terra e água, tal qual são para os irracionais, mas dota o estrelato celestial de riqueza e pensamentos divinos, os quais transcendem o concreto, rumo à essência abstrata do "além".

Atualmente ocorre o inverso, o sentido está tão concentrado no que é mero terreno, fantasiado de verdadeira filosofia, necessitando de forças para erigir-se novamente. $\mathrm{O}$ espírito tem se mostrado pobre, se satisfazendo por miudezas, traduzindo no quanto perdeu, lembrando-se que a filosofia deve guardar-se de pretender ser edificante.

Assim, adianta-se inclusive, de forma breve, a crítica pretendida neste artigo, que é a deliberação de julgamento para revelar a verdade real, não podendo esta se resumir em somatório de decisões desconexas da parte discursiva que geraria um desacordo, pois permite decidir, mas não deliberar.

Para o professor Doutor Júlio Aguiar de Oliveira (2016):

Embora se verifique um número considerável de referências à proporcionalidade em decisões de ministros do STF, não é acertado concluir que a nossa corte constitucional aplique a máxima da proporcionalidade.

A aplicação da máxima da proporcionalidade no contexto de uma decisão colegiada demanda a elaboração de uma fundamentação argumentativa que, por sua vez, depende da verificação da deliberação em sentido estrito, algo que, essencialmente por razões de natureza institucional, não se verifica no STF. (OLIVEIRA, 2016, p; 146-153).

Voltando para a específica analise Hegeliana e deixando o caso prático para logo, o filósofo acentua que é passível também de crítica, a razão que renúncia desdenhando à ciência, como se o referido entusiasmo e êxtase fosse superior à mesma, entendendo que o entusiasmo de profecia a sobrepõe crendo que a ciência fosse finita e ínfima. Todavia, há uma extensão da substância vazia, ou seja, carente de conteúdo e, portanto, superficial. 
A força do espírito, na verdade, apenas é grande na mesma proporção de sua exteriorização e profundidade, ou seja, é profunda à medida que ousa expandir-se em seu contínuo desdobramento. O tempo agora é de nascimento e trânsito para nova época. O espírito rompeu com seu "ser-aí" de até então e apresenta o atual "ser-aí" com seu representar, assim sucessivamente na tarefa de transformação. Por este motivo o espírito nunca repousa, mas sempre movimenta à frente, ininterruptamente. Hegel (2017) elucida:

o pressentimento vago de um desconhecido são os sinais precursores de algo diverso que se avizinha. Esse desmoronar-se gradual, que não alterava a fisionomia do todo, é interrompido pelo sol nascente, que revela num clarão a imagem do mundo novo. (HEGEL, 2017, p. 29)

Nesta nova fase falta a efetividade acabada, a imediatez do mundo novo e, o começo de um novo espírito é o produto de uma complexa transformação de diversas formas de cultura, assim "a efetividade desse todo simples consiste em que aquelas figuras, que se tornaram momentos de novo se desenvolvem e se dão nova figuração; mas no seu novo elemento, e no sentido que resultou do processo". (HEGEL, 2017, p.29) Há, assim, a não repetição do ser.

Cada "ser" que surge é um novo fenômeno e, para a consciência, o alto valor do "ser-aí" passado fica presente na rememoração. Na nova representação, a consciência carece de expansão e da particularização deste novo "ser", mais que isso, sobre o primeiro aprimoramento da forma, mediante o qual as diferenças são determinadas com segurança e ordenadas conforme as relações. Isto é o que Hegel entende por inteligibilidade universal, com a aparência de posse esotérica de tantos indivíduos, que nesta difusão, torna o singular “ser-aí", o próprio, infungível, produto do ciclo transformativo.

Essa forma inteligível é o que já se tem por conhecido, já comum à ciência e consciência não científica, que pode, através desta, adentrar na ciência propriamente dita. Destacando-se aqui haver corrente que insiste nesta riqueza dos materiais e na inteligibilidade, a outra despreza a inteligibilidade e se funda na racionalidade imediata e na divindade, submetendo tudo à ideia do absoluto, que desse modo parece ser reconhecida em tudo e desenvolvida numa ciência ampla realizável, como se existisse uma fórmula única, repetível, idêntica e verdadeira, adaptada pelo sujeito sabedor aos dados presentes:

O material é mergulhado de fora nesse elemento tranquilo. Isso porém - e menos ainda fantasias arbitrárias sobre o conteúdo-não constitui o cumprimento do que se exige, a saber, a riqueza que jorra de si mesma, a diferença das figuras que a sim mesmas se 
determinam. Trata-se antes de um formalismo de uma só cor, que apenas atinge a diferença do conteúdo, e ainda assim porque já o encontra pronto e conhecido. (HEGEL, 2017, p.29)

Por isso Hegel afirma que neste sentido "se depara com um método especulativo onde é válido precipitar no abismo o vazio o que é diferente e determinado, sem que isso seja consequência do desenvolvimento nem se justifique a si mesmo" (HEGEL. 2017. p 31).

Relevante a distinção de saberes, evidenciando a genuína filosofia da prática metódica desprovida do real "ser-aí", carente, portanto, de essencialidade. Prossegue o filósofo que é como se considerar um "ser-ai" qualquer, como é no absoluto, não consiste outra coisa senão em dizer que dele se falou como se fosse um certo algo, mas que no absoluto, no $\mathrm{A}=\mathrm{A}$, não há nada disso, pois ali tudo é uma coisa só. É ingenuidade de quem está vazio de conhecimento pôr esse saber único - de que tudo é igual no absoluto - em oposição ao conhecimento diferenciador e pleno, frisando que: “Ou então fazer de conta que seu absoluto é a noite em que todos os gatos são pardos, como se costuma dizer". (HEGEL, 2017, p. 31)

O genuíno reconhece a si mesmo no absoluto ser-outro, esse éter como tal, é o fundamento e o solo da ciência, ou do saber em sua universalidade. O começo da filosofia faz a pressuposição ou exigência de que a consciência se encontre nesse elemento. Todavia, tal elemento apenas alcança sua perfeição no movimento de "vir-a-ser". É a pura espiritualidade como universal, que tem o modo de imediatez simples (HEGEL, 2017).

É de se denotar a riqueza tamanha que se conclui da presente análise:

Esse simples, quando tem como tal a existência, é o solo da ciência, que é o pensar, o qual só está no espírito. Porque esse elemento, essa imediatez do espírito é, em geral, o substancial do espírito, é a essencialidade transfigurada, a reflexão que é simples ela mesma, a imediatez tal como é para si, o ser que é reflexão sobre si mesmo. (HEGEL. 2019. p. 37)

A vida é aquela que suporta a morte e nela se conserva, é a vida do espírito, o qual encontra sua verdade na medida em que se encontra no dilaceramento absoluto. O espírito não é potência, tal qual o positivo afasta-se do negativo. $\mathrm{O}$ espírito apenas é potência quando encara diretamente o negativo e se demora junto dele, reagindo e fundindo o ser. Ou seja, converte-se o negativo em ser.

É o mesmo poder que se atribui ao sujeito quando ao suprassumir a imediatez abstrata, dando-se em seu elemento um "ser-aí” determinante. Assim sendo, o sujeito é a substância verdadeira, o "ser" ou a imediatez. Não há imediação entre o sujeito e objeto. O "ser" é a imediação mesma, a própria reação fenomênica. (HEGEL, 2017) 
No entanto, pretende-se discorrer da essência do "ser", sujeito que conhece e é conhecido. O círculo fechado de movimentos e momentos como sua substância é a relação imediata e efetivada em sua conexão com outra coisa, ganhando um "ser-aí" próprio e uma liberdade à parte. Assim, a energia do apenas puro "Eu” é o "ser". (HEGEL, 2017)

Serve a famigerada frase de Heráclito de Éfeso: "Ninguém pode se banhar no mesmo rio duas vezes, porque nem ele, nem o rio, serão os mesmos" (BITTAR; ALMEIDA. 2015, p. 89).A cada momento o "ser" é, num ciclo transformativo, jamais repetível. Trata-se, pois de um fenômeno espiritual.

\section{A INTELIGÊNCIA ARTIFICAL PARA JULGAMENTOS JUDICIAIS VIRTUAIS}

Introduzindo a conexão dos temas até aqui propostos, inicialmente mostrou-se a celeridade da globalização quanto à influência virtual nas relações. Hegel (2017) por sua vez demonstra a formação do genuíno "ser”, resultando da relação sujeito e objeto.

Assim, segundo o sítio eletrônico do Tribunal de Justiça de Minas Gerais:

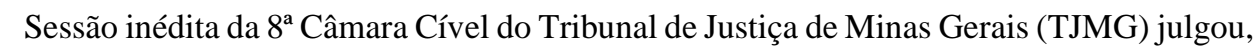
com apenas um click no computador, um total de 280 processos. Em menos de um segundo, todos os processos foram julgados. A sessão foi presidida pela desembargadora Ângela Rodrigues, que acionou a plataforma digital que continha os votos dos integrantes da Câmara. "Belo Horizonte foi palco de uma das sessões mais importante do Poder Judiciário de todos os tempos. Trata-se de um grande salto em direção ao futuro", disse o $1^{\circ}$ vice-presidente do Tribunal de Justiça de Minas Gerais (TJMG), desembargador Afrânio Vilela, na manhã de hoje, 7 de novembro.

Esse julgamento somente foi concluído, de forma célere, devido à ferramenta Radar que identificou e separou recursos com idênticos pedidos. Os relatores elaboram o voto padrão a partir de teses fixadas pelos Tribunais Superiores e pelo próprio Tribunal de Justiça mineiro. Para o presidente do TJMG, desembargador Nelson Missias de Morais, os avanços na tecnologia de informação, como o inaugurado hoje, fazem parte do planejamento estratégico do Tribunal e são prioridade da atual gestão, com o objetivo de tornar os julgamentos mais céleres, beneficiando o cidadão. "Até meados do próximo ano, todos os processos em Minas já estarão tramitando por meio eletrônico, tornando mais ágeis as decisões e proporcionando enorme economia de recursos para o Tribunal", completou. (TJMG, 2018, p. 1)

Os julgamentos virtuais funcionam a partir de inteligência artificial, da qual ordenada por ciências exatas, a matemática, na forma de algoritmo. A Universidade Estadual de São Paulo (USP) realizou pesquisas sobre o tema e resumidamente elucida: 
As Redes Neurais Artificiais denominadas neste trabalho apenas como redes neurais, são sistemas de processamento de informação formadas pela interconexão entre unidades simples de processamento, denominadas neurônios artificiais. Os neurônios artificiais recebem essa denominação porque foram originados a partir de um modelo matemático de um neurônio biológico; a principal propriedade desta arquitetura é a sua capacidade de aproximação universal e de aprendizado.

Treinar uma rede neural significa ajustar os pesos da rede de forma que a saída coincida com um certo valor desejado para cada entrada. Existem alguns algoritmos de treinamento que, além do ajuste de pesos, provocam mudanças na própria arquitetura da rede, como a criação ou eliminação de neurônios (...) (CASTRO, 2003, p. 26).

Os professores Castro, (2003) experts no assunto, demonstram com detalhes como funciona a inteligência artificial. De fato é uma arte, imitando a hipótese de inteligência, mas não é inteligível. Se é artificial, deixou de "ser", embora a arte da réplica da inteligência, não é inteligência.

A inteligibilidade, como demonstrou Hegel (2017), é a concatenação de vários fenômenos rememorados, ou seja, implica vivência de história do ser, ora interação do sujeito e objeto.

Segundo as ciências exatas, a inteligência artificial:

Uma rede neural artificial é composta por várias unidades de processamento, cujo funcionamento é bastante simples. Essas unidades, geralmente são conectadas por canais de comunicação que estão associados a determinado peso e fazem operações apenas sobre seus dados locais, que são entradas recebidas pelas suas conexões. O comportamento inteligente de uma Rede Neural Artificial vem das interações entre as unidades de processamento da rede.

A operação de uma unidade de processamento, proposta por McCullock e Pitts em 1943, pode ser resumida da seguinte maneira: Sinais são apresentados à entrada;

Cada sinal é multiplicado por um número, ou peso, que indica a sua influência na saída da unidade; É feita a soma ponderada dos sinais que produz um nível de atividade; Se este nível de atividade exceder um certo limite (threshold) a unidade produz uma determinada resposta de saída. (CASTRO, 2003, p. 26).

É, todavia, desprovida de espírito a inteligência artificial, cujo magistério hegeliano:

O que esta Fenomenologia do espírito apresenta é o vir-a-ser da ciência em geral ou do saber. O saber, como é inicialmente - ou o espírito imediato - é algo carente-de-espírito: a consciência sensível. Para tornar-se saber autêntico, ou produzir o elemento da ciência que é seu conceito puro, o saber tem de se esfalfar através de um longo caminho. Esse vira-ser, como será apresentado em seu conteúdo e nas figuras que nele se mostram, não será o que obviamente se espera de uma introdução da consciência não cientificará ciência; e também será algo diverso da fundamentação da ciência (HEGEL, 2017. p 38)

Eis a distinção antagônica da inteligência artificial e da autêntica. Esta movida por espírito e aquela desprovida, razão da qual não é ciência, sem consciência. Não apenas é inservível como inteligência em substituição à humana, mas sobretudo aos casos de julgamentos judiciais, principalmente quando toca aos princípios basilares do direito.. 
Ora, o indivíduo julga o seu par, o espírito divino concede entendimento para a justa distribuição da justiça, mas não uma lógica matemática exteriorizada e inerte ao ser. Quando Hegel (2017) apresenta que a tarefa de conduzir o indivíduo desde seu estado inculto até o saber, devia ser entendida em seu sentido universal, o espírito consciente de si na sua formação cultural. O tocante à relação entre os dois sujeitos, cada momento no indivíduo universal se mostra conforme o modo como obtém sua forma concreta e sua configuração própria.

A crítica hegeliana ao seu tempo assevera que:

Nos tempos modernos, ao contrário, o indivíduo encontra a forma abstrata pronta. $\mathrm{O}$ esforço para apreendê-la e fazê-la sua é mais o jorrar-para-fora, não imediatizado, do interior, e o produzir abreviado do universo, em vez de ser um brotar do universal a partir do concreto e variedade do ser-aí (HEGEL, 2017, p.42)

Assim, não respeitando a variedade do "ser-aí", concentram 280 casos para serem julgados pela matemática de artifícios. A obra de Hegel (2017) parece mais moderna do que nunca, pois em tempos atuais o indivíduo encontra a forma abstrata pronta, omitindo-se a fenomenologia de um terceiro para com o outro a formar o "ser".

É imprescindível que cada um dos 280 casos julgados virtualmente sejam revistos, ou melhor, sejam "vistos", eis que até o presente não houve quem os manejasse de forma humana, pois o elemento do "ser-aí" imediato é a determinidade pela qual essa ciência se diferencia das outras. (HEGEL, 2017). A ciência desses itinerários é a ciência da experiência que faz a consciência; a substância é tratada tal como ela e seu movimento são objetos da consciência.

A experiência, segundo Hegel (2017), é justamente o nome desse movimento em que o imediato, o não experimentado, ou seja, o abstrato-quer do sensível, que do simples apenas pensando - se aliena e depois retorna a si dessa alienação; e por isso - como é também propriedade da consciência - somente então é exposto em sua efetividade e verdade. Então impossível a verdade propriamente dita, nos julgamentos sem a consciência.

Há necessidade da relação do julgador e o objeto, ou seja, o caso a ser julgado. A desigualdade que se estabelece na consciência entre o "Eu" e a substância - que é o seu objeto - é a chamada diferença entre eles, o que apenas haverá entre um juiz togado e um processo em mãos. Hegel denomina este fato de "negativo geral". Pode considerar-se como falha dos dois, mas é sua alma, ou seja, é o que os move.

Foi por isso que alguns dos antigos conceberam o vazio como o motor. De fato, o que conceberam foi o motor como o negativo, mas ainda a não o negativo como o si. Ora, se 
esse negativo aparecesse primeiro como desigualdade do Eu em relação ao objeto, é do mesmo modo desigualdade da substância consigo mesma. O que parece ocorrer fora dela - ser uma atividade dirigida contra ela - é o seu próprio agir; e ela se mostra ser essencialmente sujeito. (HEGEL. 2017. p. 44)

Aqui, encerra a fenomenologia do espírito, segundo Hegel. Portanto, imprescindível o "Eu" e o "outro" para a relação de negatividade formar a Alma, que assim move o fluxo transformativo do "ser". Assim, se expandem nesses elementos os momentos do espírito da forma de simplicidade, que entende seu objeto como si próprio. Então, esses momentos deixam de ser oposição entre o "ser" e o saber de forma distinta, mas na "simplicidade do saber" ficam como o verdadeiro na forma de verdadeiro e a sua diversidade é apenas de conteúdo. O seu movimento, nesse elemento se organiza em um todo, é o que Hegel (2017) chama de Lógica ou Filosofia especulativa.

Quando o sistema de experiência do espírito (consciência) capta somente sua aparição, então aparecerá como apenas negativo o processo que conduz por meio do sistema de experiência à ciência do verdadeiro que está na forma do verdadeiro.

Existe a hipótese de alguém se dispensar do negativo enquanto falso e conduzido sem mais delongas à verdade, no afã de manter-se como falso, pretendendo atingir apenas no "finalmente" do processo com o rótulo de verdadeiro, embora sem merecê-lo, como um atalho sem sucesso.

Hegel (2017) responde a isso a partir do ponto de vista sobre a natureza do negativo que toma como falso em geral. As representações a propósito impedem, obviamente, o acesso à verdade. Destarte tem-se ocasionalmente de falar sobre o conhecimento matemático, que o saber filosófico considera como o ideal que a filosofia deve esforçar-se para atingir, mas até o presente momento não obteve êxito.

O falso - pois só dele aqui se trata - seria o Outro, o negativo da substância, a qual é o verdadeiro, como conteúdo do saber. Mas a substância mesma é essencialmente o negativo; em parte como diferenciação e determinação do conteúdo, em parte como um diferenciar simples, isto é, como Si e saber em geral. É bem possível saber falsamente. Saber algo falsamente significa que o saber está em desigualdade com sua substância. Ora, essa desigualdade é precisamente o diferenciar em geral, é o momento essencial. É dessa diferenciação que provém sua igualdade; e essa igualdade que veio-a-ser é a verdade. (HEGEL. 2017. p. 45)

O algoritmo não tem a capacidade consciente para reagir com um segundo elemento que sequer possa ser chamado "outro", pois "outro" idealiza que há um primeiro semelhante ao segundo.

O professor de Engenharia de Elétrica e Computação da Universidade Estadual de Campinas, Castro (2003), leciona: 
A auto-organização demonstrada nas redes neurais não-supervisionadas, envolve, o processo de competição e o processo de cooperação entre os neurônios da rede. Muitos pesquisadores têm utilizado esse tipo de rede como detector de características, dada sua capacidade de aprender a discriminar estímulos ocorrendo em partes especialmente diferentes.

$\mathrm{O}$ treinamento pode-se assim dizer, inicia quando um exemplo é mostrado à rede e termina quando todas as conexões estão devidamente ajustadas (treinadas) para reconhecer os exemplos mostrados à rede (ou pelo menos uma boa parte dos exemplos). A partir deste momento a Rede Neural está pronta para a fase de testes e, a seguir, para a execução.

Do conjunto de dados que será submetido à rede, pode-se dizer que, quanto mais completo seja, mais tempo computacional (processamento) será utilizado para ajustar as conexões e, certamente, melhor será o seu treinamento.

Existem diferentes algoritmos de aprendizagem utilizados no treinamento não supervisionados, entre os mais conhecidos temos a aprendizagem de Hebbian, o aprendizado competitivo, aprendizado winner-take-all entre outros.

O material relacionado com redes neurais com treinamento não supervisionado é apresentado a continuação. (CASTRO, 2019, p. 14)

O julgamento virtual, enquanto Direito, este ciências humanas ou sociais aplicadas, não pode(ria) ser regido pela engenharia de computação, ora ciências exatas. Não que o procedimento virtual seja evitado, do contrário, é muito eficiente enquanto ferramenta, jamais como consciência. Eis a questão.

Na filosofia Helegiana, este aborda:

"Quanto às verdades matemáticas, ainda seria menos tudo como geômetra quem soubesse os teoremas de Euclides exteriormente, sem conhecer suas demonstrações (ou conhecer interiormente, para exprimir-se por contraste). Também não seria considerado satisfatório o conhecimento da relação bem conhecida entre os lados do triângulo retângulo, se fosse adquirido medindo muitos triângulos retângulos. Mas a essencialidade da demonstração não tem ainda, mesmo no conhecimento matemático, a significação e a natureza de ser um momento do resultado mesmo; ao contrário, no resultado da demonstração some e desvanece. Sem dúvida, como resultado, o teorema é reconhecido como um teorema verdadeiro. Mas essa circunstância, que se acrescentou depois, não concerne ao seu conteúdo, mas sí a relação para com o sujeito. O movimento da prova matemática não pertence à quilo que é objeto, mas é um agir exterior à Coisa.

Assim não é a natureza do triângulo retângulo que se decompõe tal como é representada na construção necessária à demonstração do teorema que exprime sua relação; todo o processo de produzir o resultado é um caminho e um meio de conhecimento" (HEGEL, 2017.p. 47)

Em relação ao conhecimento filosófico, diversamente do matemático, o "vir-a-ser" do "serai" como "ser-aí" é diferente do "vir-a-ser" da essência, ou melhor, da natureza interior da coisa. É que, primeiramente, o conhecimento filosófico possui os dois, enquanto o conhecimento matemático apenas apresenta o "vir-a-ser" do "ser-aí", isto é, do ser da natureza da "coisa" no conhecer como tal deva ser. Pelo conhecimento filosófico unem também esses dois movimentos 
particulares. O nascer interior, ou o "vir-a-ser" da substância, é inseparavelmente transitar para o exterior ou para o "ser-aí", ou seja, é "ser” para o outro.

Ao contrário, o "vir-a-ser" do "ser-aí" é o recuperar a si mesmo na essência. O movimento então é assim o duplo processo e "vir-a-ser" do todo, de modo que cada momento põe ao mesmo tempo o outro, e por isso cada qual tem em si, como dois aspectos, ambos os momentos, sendo que eles, conjuntamente, constituem o todo, enquanto se dissolvem a si mesmos e se fazem momentos seus (HEGEL. 2017. p. 47).

Na matemática é diferente. Seu conhecer, a intelecção é para a Coisa um agir exterior, seguindo a partir daí a verdadeira Coisa que é por ele alterada. O meio desse conhecimento, a construção e demonstração, até contém proposições verdadeiras; mas deve-se dizer que o conteúdo é falso, pois, por exemplo, a solução do Teorema de Euclides, se desmembra o triângulo, e suas partes são articuladas em outras figuras que a construção quem faz nele surgir. Apenas ao final que se restabelece o triângulo, aquele que justamente se tratava, mas que se perdeu de vista no processo demonstrativo, reduzido a peças que compreendiam partes de outras totalidades.

É nisso, então que nesse ponto se ressalta a negatividade do conteúdo, ao dizer que o conteúdo é falso, que por isso é uma falsidade o desvanecer dos pensamentos que se tinham por fixos no movimento do conceito.

\section{DECISÃO JUDICIAL: CIÊNCIAS EXATAS E CIÊNCIAS HUMANAS}

Segundo Hegel (2017), a matemática esnoba a filosofia, justamente por causa desse conhecimento "defeituoso", cuja evidência reside apenas na pobreza de seu fim e na deficiência de sua matéria, portanto, é algo que a filosofia despreza.

O fim, o conceito da matemática é a grandeza, justamente a relação inessencial carente de conceito. Por isso mesmo, o movimento do saber matemático perpassa a superfície, não toca a Coisa mesma, nem a essência ou o conceito. Portanto, não é um conceber. Jamais pode-se dar que um julgamento virtual concebeu um parecer dedisium.

A matéria onde a matemática preserva um tesouro gratificante de verdades é o espaço e o uno. O espaço é o "ser-aí", no qual o conceito se inscreve suas diferenças, como num elemento vazio e morto, no qual as diferenças são igualmente imóveis e sem vida. O efetivo não é algo 
espacial, como é tratado na matemática; com tal inefetividade, como são as coisas da matemática, não se ocupa nem a intuição sensível concreta nem a filosofia. Por conseguinte, nesse elemento inefetivo, apenas se proposições mortas e rígidas. Em cada uma dessas proposições pode parar, a seguinte recomeça tudo por sua conta, sem que a primeira se movesse até ela, e sem que assim surgisse alguma conexão necessária através da natureza da Coisa mesma. (HEGEL. 2017. p. 48)

Orgulha-se o Egrégio Tribunal de Justiça Mineiro sobre os julgamentos por inteligência artificial que funcionam a partir de ciência matemática:

De acordo com o $1^{\text {o }}$ vice-presidente, desembargador Afrânio Vilela, a tecnologia empregada nesse novo tipo de julgamento foi totalmente desenvolvida pelos servidores da Diretoria de Informática. O magistrado explicou que os profissionais da informática, utilizando-se da tecnologia da informação e vertentes da inteligência artificial, criaram a ferramenta Radar, que identifica e separa recursos com pedidos similares. (TJMG, 2018, p. 2)

Pertinente a concepção trazida por Hegel (2017), quanto ao espaço e tempo, pois as decisões repetidas não poderiam servir como total fundamento de fatos por vir, como se fosse uma regra matemática aplicada em qualquer equação. A matemática imanente não põe o tempo como o tempo, frente ao espaço, como a segunda matéria de sua consideração. Tal matéria aplicada trata de fato do tempo, do movimento e de várias outras coisas efetivas. No entanto, toma-se da experiência as proposições sintéticas, isto é, proposições sobre suas relações que são determinadas por meio de seu conceito, e apenas essas aplicam as suas fórmulas. Enfim, não a alma da consciência, mas artificialmente, uma réplica infiel da verdade que decide o futuro do ser e ousa dar a isto o nome de Justiça.

O que serve para a decisão judicial é o fundamento jurídico, não a repetição do que um dia foi em outro espaço e tempo, de caso distinto. Portanto, para Hegel, a matemática aplicada oferece em abundância o que chama de demonstrações:- como a do equilíbrio da alavanca e a relação entre o espaço e o tempo no movimento da queda livre. Mas que sejam dadas e aceitas como demonstrações, prova apenas a grande necessidade da prova para o conhecimento, pois quando não tem mais provas, valoriza até sua aparência vazia e ali encontra alguma satisfação.

Uma crítica dessas demonstrações seria tão digna de nota quanto intrutiva; de um lado, por expurgar a matemática dessas bijuterias, e, de outro, por mostrar seus limites, e, portanto, a necessidade de um outro saber(...)

(...) mas o tempo é o próprio conceito aí-essente. O princípio da grandeza - a diferença carente de conceito, e o princípio da igualdade, a unidade abstrata sem vida, não são capazes de apreender o tempo, essa pura inquietude da vida e diferenciação absoluta. (HEGEL. 2017.p. 49) 
O intento de padronizar o sujeito como um "ser" é técnica antiga, que o sistema penal judicial se reinventa, seja desta atualidade como a inteligência virtual que tem o programa de um elemento padronizado como o correto, ou como Focault (1999) citando Lombrozo explica, mas que não por Lei, sim pela autoridade Estatal:

Meu objetivo será mostrar-lhes como as práticas sociais podem chegar a engendrar domínios de saber que não somente fazem aparecer novos objetivos, novos conceitos, novas técnicas, mas também fazem nascer formas totalmente novas de sujeitos e de sujeitos de conhecimento. O próprio sujeito de conhecimento tem uma história, a relação do sujeito com o objeto, ou, mais claramente, a própria verdade tem uma história." (FOCAULT, 1999, p. 8)

A desigualdade é compelida à igualdade, mas que seja aquela que serve à manutenção do poder, da que intitulam "ordem pública”, expressão vaga que comporta a interpretação pretendida ao favor do Excelentíssimo. Se ninguém é igual, nem o tempo se repete, se há a Lei e o devido processo legal, desnecessário configurar no computador o modelo de cidadão a ocupar a sociedade

\section{CONSIDERAÇÕES FINAIS}

Os julgamentos virtuais funcionam a partir de inteligência artificial de engenharia matemática, algoritmo, do qual foi comprovado não permitir a essência imprescindível do julgador, ora consciência do "Eu" para com o objeto, ou seja, inexiste o "ser".

O "ser" precisa estar presente para definir algo no vazio lhe apresentado, ora a resposta à lide processual. A equação matemática não decide mérito, até mesmo porque suas ciências são as exatas, ora imutáveis, não as humanas sociais aplicáveis conforme o tempo e espaço que se diferem continuamente, donde emerge o Direito.

O orgulho da equivocada eficiência de julgar centenas de processos em menos de um segundo a partir de repetições de outros julgados, não confecciona o devido processo legal, muito distante da filosofia jurídica - alma da questão.

É uma réplica de análise humana, letra morta, que no modismo de tempos líquidos para satisfazer o imediatismo de celeridade e resposta frente as ondas de notícias de injustiças, acaba por não solucionar e agrava a má distribuição da Justiça. 
Como exemplo, vale lembrar dos tempos de ouro do avanço das ciências biológicas, que tal qual hoje a matemática se atreve invadir as ciências jurídicas, preteritamente as biológicas ousou introduzir o método lombrosiano como meio eficiente, padronizando o bio-perfil do delinquente, intentando padronizar o "ser".

\footnotetext{
"Nossos sistemas penais reproduzem sua clientela por um processo de seleção e condicionamento criminalizante que se orienta por estereótipos proporcionados pelos meios de comunicação de massa. (...)Os órgãos do sistema penal selecionam de acordo com esses estereótipos, atribuindo-lhes e exigindo-lhes esses comportamentos, tratando-os como se comportassem dessa maneira, olhando-os e instigando todos a olhá-los do mesmo modo, até que se obtém, finalmente, a resposta adequada ao papel assinalado.” (ZAFFARONI, 2001, p. 133)
}

Hegel (2017) demonstra o que é o "ser", ora distinto de qualquer padronização ou fórmula, tampouco de sequências algoritmos matemáticos camuflados de algo ainda pior, que são decisões pretéritas de outros fenômenos espirituais, como se o ser sofresse padronização, furtando do humano o seu ser.

\section{REFERÊNCIAS}

ALEXY, Robert. Teoria Discursiva do Direito. Tradução de Alexandre Travessoni Gomes Trivosonno, 1. ed. Editora Forense, 2014.

BAUMAN, Zygmunt. Vida líquida. 2a edição, Editora Zahar: Rio de Janeiro, 2009.

BAUMAN, Zygmunt. Tempos líquidos. 12 Edição, Editora Zahar: Rio de Janeiro, 2017.

BECHARA, Ana Elisa Libertore Silva. apud BECK, Ulrich. Discurso de emergência e política criminal: O futuro do Direito Penal Brasileiro., Revista da Faculdade de Direito da Universidade de São Paulo, v. 103, jan. 2008.

BITTAR, Eduardo C. B; ALMEIDA, Guilherme Assis de. Curso de filosofia do direito. $11^{\mathrm{a}}$ Edição, Editora Atlas S.A: São Paulo, 2015.

BRANDÃO, Cláudio. Tipicidade Penal. 2.ed. Rio de Janeiro: Forense, 2010.

CARNELUTTI, Francesco. As misérias do processo penal. São Paulo: Saravanda, 2012.

CASTRO, Leandro. Análise e Síntese de Estratégias de Aprendizado para Redes Neurais Artificiais. 2003. Dissertação (Mestrado em Engenharia da Computação) - Universidade Estadual 
de Campinas, Campinas, 2003. Disponível em: http://www.dca.fee.unicamp.br/ vonzuben/research/lnunes_mest.html. Acesso em: 19 fev. 2019.

FOUCAULT, Michel. A Verdade e as Formas Jurídicas. 2.ed. Rio de Janeiro: Nau Ed., 1999. HEGEL, Georg Wilhen Friedrich. Fenomenologia do espírito. 9.ed. Rio de Janeiro: Vozes., 2017. HEIDEGGER, Martin. Carta ao humanismo. 2. ed. São Paulo: Centauro. 2005.

KANT, Immanuel. Fundamentação da Metafísica dos Costumes. Edições 70, p.96.

OLIVEIRA, Júlio Aguiar de. A deliberação como condição de aplicação da proporcionalidade. Revista Brasileira de Direito. v. 12(2), p.146-153. 2016. Disponível em: https://seer.imed.edu.br/index.php/revistadedireito/article/view/1620. Acesso em 07 de fev de 2019.

TRIBUNAL DE JUSTIÇA DE MINAS GERAIS. [Noticias]. TJMG utiliza inteligência artificial em julgamento virtual. Belo Horizonte, 07 nov. 2018. Disponível em:https://www.tjmg.jus.br/portal-tjmg/noticias/tjmg-utiliza-inteligencia-artificial-emjulgamento-virtual.htm\#.XGapQVVKhdg. Acesso em: 08 de fev 2019.

ZAFFARONI, Eugenio Raul. Em busca das penas perdidas. 5. ed. Rio de Janeiro: Revan. 2001.

\title{
BEING AND VIRTUAL JUDGMENTS
}

\begin{abstract}
The hallmark of postmodernity has been the immediacy of satisfaction. We seek at all costs to achieve the satisfaction of the desired object in the shortest possible time, attributing to it the so-called effectiveness. The speed provided by virtualization affected human relations in several orders, especially the jurisdictional order, which eventually reached the affective bases in the name of the proclaimed progress. The implementation of a system that minimizes and sometimes replaces human cognitive analysis has invaded the space of being that judges and what is judged, oblivious to the intrinsic rationality in the legal social relation as human sciences, thus providing a robotization of decisions that directly affect the whole a society. Therefore, in this work, a theoretical research and conceptual analysis focused on "being" in Hegelian dialectics will be used as a methodological technique.
\end{abstract}

Keywords: Ser. Virtual Judgment. Applied social sciences. Philosophy 